power source and sometimes without communication with their operators. This mimics real disaster scenarios, in which connectivity can be spotty. DARPA expects that this constraint will encourage teams to increase their robots' capacity to map out, plan and act independently. "Success at this level would be a huge achievement," says Pratt.

Robots have become reasonably good at sensing and moving, says Henrik Christensen, chair of robotics at the Georgia Institute of Technology in Atlanta. Remote sensors on SAFFiR, for example, measure force and body position (part of what allows the robot to find its centre of gravity); cameras and software let it monitor distance and potential obstacles. CHIMP, a robot built by a team at Carnegie Mellon University in Pittsburgh, Pennsylvania, transitions deftly from trundling along on four tank treads to standing on two.

But the machines are "not much good at making judgements, like deciding if something is a drill or a cup, or figuring out which is relevant to what it needs to do", Christensen says. "These things turn out to be very hard, and humans are much better at them."

\section{DIVISION OF LABOUR}

Some teams want to better translate what a robot sees into something that a human operator can easily understand. The goal is to create an efficient human-robot team that is "more like having two humans, where one directs the other", says Todd Danko, who leads a DRC team from defence contractor Lockheed Martin. In fact, Yanco's analysis found that teams with better-designed human-robot interface platforms were better at completing contest tasks.

"I think a big part of this contest is that it will get people to embrace a kind of 'shared autonomy' between the humans and the robots," says James Kuffner, a roboticist at Google in Mountain View, California. "That means thinking about what's necessary for the human to do, for the robot to do, and for how to tell that to the robot."

DARPA-sponsored robot contests in the mid-2000s focused on autonomous transport and were driven by an interest in taking human couriers off the explosive-strewn streets of Iraq and Afghanistan. These races helped to spawn interest in driverless cars from companies such as Google.

In more recent years, the defence department has recommended that the military change its approach to autonomous systems and focus on collaboration between people and technology. Unlike autonomous trucks and unmanned drones, the robots under development for the current competition will be accomplices - not mere substitutes - in helping humans to get difficult jobs done.

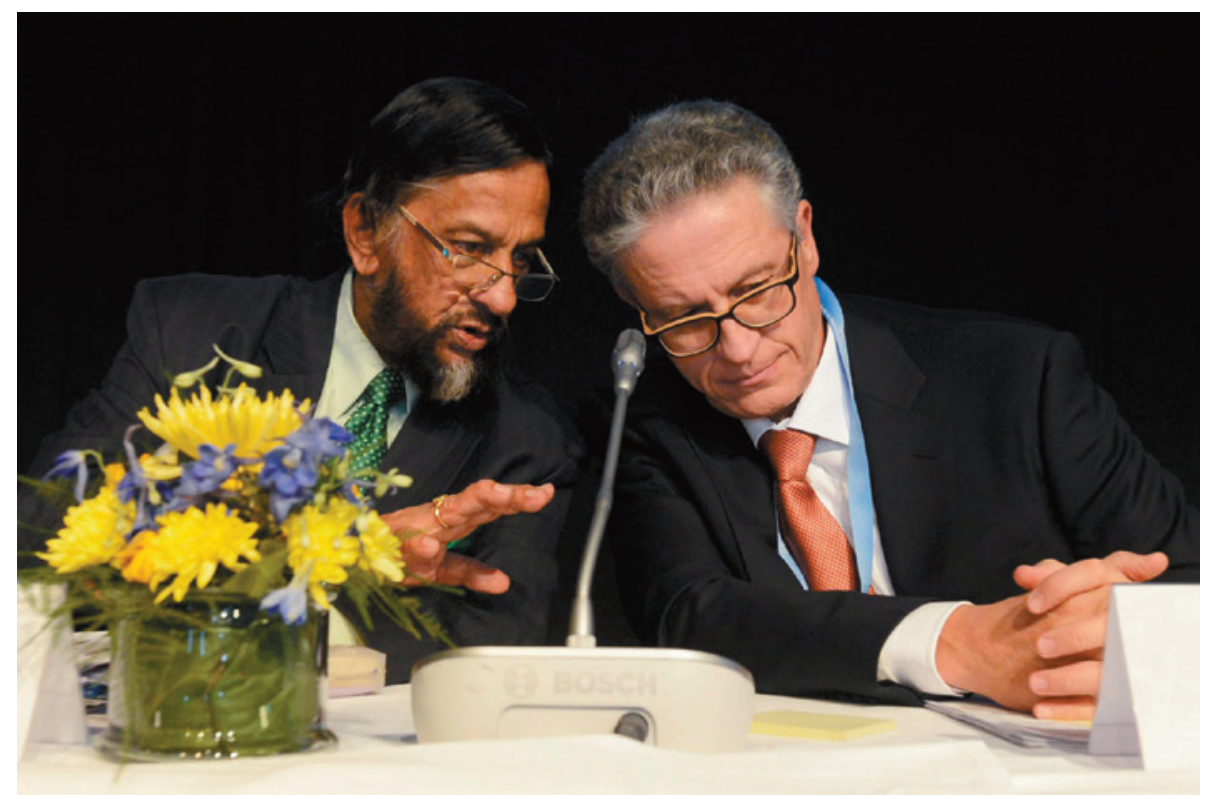

Former IPCC head Rajendra Pachauri (left) consults with potential successor Thomas Stocker.

POLICY

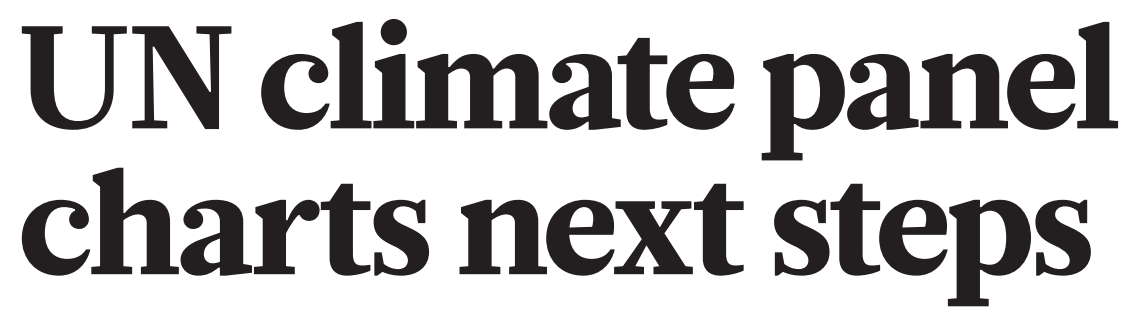

Intergovernmental Panel on Climate Change prepares for
new leadership and another assessment of climate science.

\section{BY JEFF TOLLEFSON}

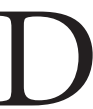
espite calls for change, the next United Nations climate assessment will take much the same form as the last one, the panel charged with producing the recurring reports announced on 27 February. The decision comes just days after the panel's long-time leader resigned in the middle of a sexual-harassment investigation.

Meeting in Nairobi from 24 to 27 February, the United Nations Intergovernmental Panel on Climate Change (IPCC) made several minor adjustments to its assessment process. The changes aim to engage more scientists, in part by boosting the representation of developing nations in the group's governing body. But the basic framework will continue to comprise a comprehensive assessment published every five to seven years plus two or three special reports on specific topics. The fifth and most recent IPCC climate assessment, which was completed last year, concluded that it is "extremely likely" that humans are responsible for the bulk of recent global warming.

"The overall structure remains, but some key aspects of its mode of operation have been improved to facilitate a fuller participation of all scientists, in particular from developing countries," says IPCC vice-chair Jean-Pascal van Ypersele, a climatologist at the Catholic University of Louvain in Louvain-la-Neuve, Belgium. "This was a key thing I think the IPCC needed to do."

The meeting follows the sudden departure of Rajendra Pachauri, who has headed the IPCC since 2002 and whose term was due to end in October. Pachauri is under investigation over allegations that he sexually harassed a colleague at the Energy and Resources Institute in New Delhi, of which he is director. He has denied the claims but elected to step down on 24 February, soon after announcing that he would not be attending the Nairobi meeting.

"We cannot ignore the resignation of Dr. Pachauri, but the allegations against him ... do not relate to the IPCC," said IPCC secretary Renate Christ during a press conference on 27 February. Christ said that the panel will, however, ensure that it maintains an atmosphere in which "everyone's rights are respected and upheld".

Ahead of the meeting, some scientists involved in the IPCC argued that the 
assessment process is too slow and requires too much time from the more than 2,000 scientists from around the world who volunteer for duty. Some have advocated that the IPCC put less energy into monumental assessments and more into shorter reports that focus on major scientific and policy debates. During the last major assessment, the IPCC released special reports on renewable energy and the risks of extreme weather, but even those were major undertakings.

Christopher Field, co-chair of the working group on impacts and adaptation for the most recent assessment, says that there are ways to streamline the process, but maintains that the value of the IPCC comes from the give and take between scientists and governments. "Operationally, it is hard to imagine a way to capture this unique value without key process steps, including multiple rounds of monitored review and line-by-line approval of summaries for policy-makers," he says.

\section{OPEN UP}

At the meeting, IPCC members said that the next assessment should have a greater focus on specific regions and include a broader review of non-English scientific literature, with more involvement of science writers and communications experts to help reach a broader range of people.

The panel also wanted to open itself up to researchers who have been seeking access to the closed-door meetings in an effort to study the assessment process and the institution itself; research proposals will be evaluated on a case-by-case basis.

"That is indeed a major step forward toward both increased transparency of the IPCC process and eventually finding ways to improve it," says Michael Oppenheimer, a climate scientist at Princeton University in New Jersey who is part of a team of researchers seeking such access.

Oppenheimer has advocated reforms that would emphasize smaller, faster assessments while decreasing the workload for scientists. He says that the latest decision largely represents "business as usual", but does open the door for improvements. In particular, he credited the IPCC for emphasizing communications and engagement with developing countries. "This is important and needs to be done," he says.

The IPCC will hold its leadership election in October. Candidates include van Ypersele and Thomas Stocker, a climate scientist at the University of Bern who co-led the working group that wrote the physical-science portion of the report during the most recent assessment. Field, who is founding director of the department of global ecology at the Carnegie Institution in Stanford, California, says that he, too, is likely to run.

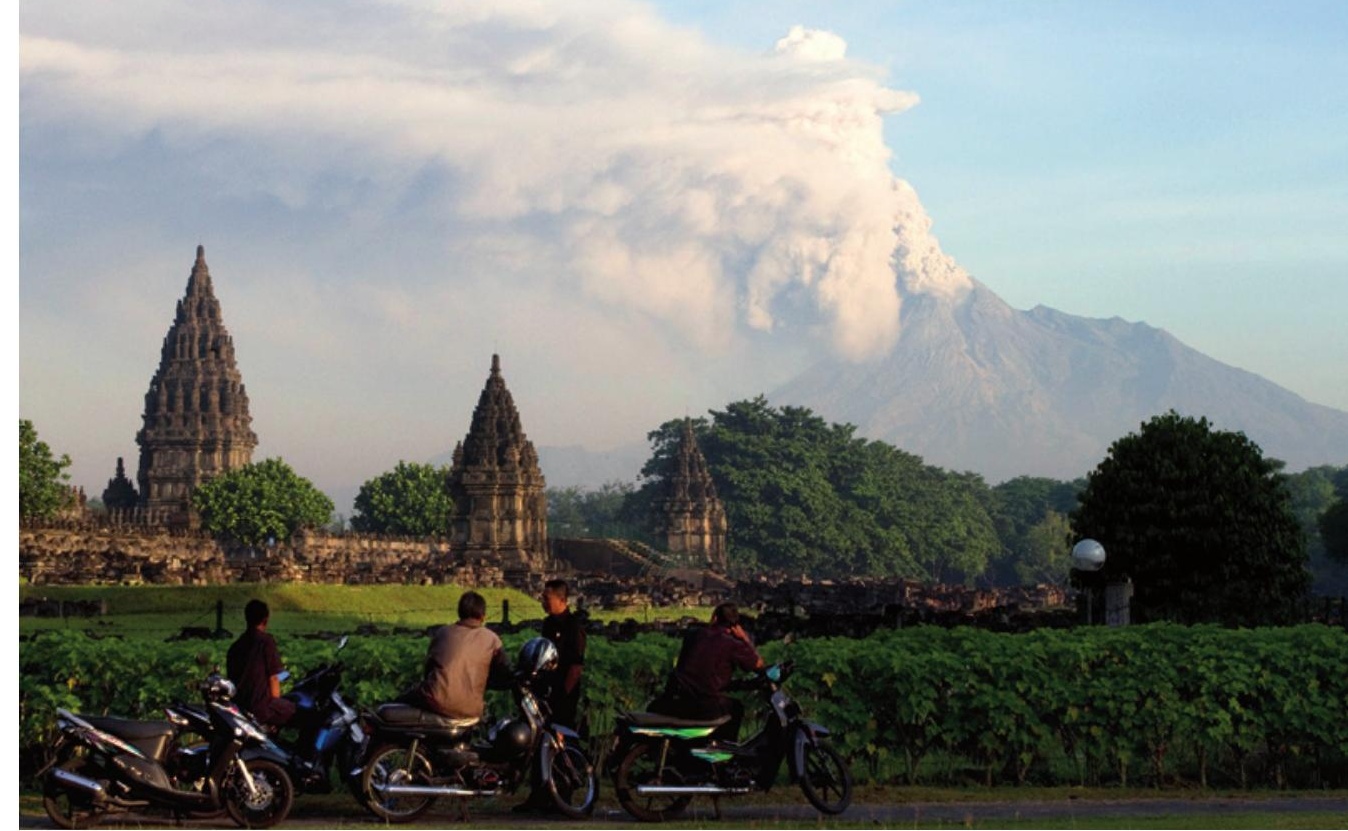

Mount Merapi, the most active volcano in Indonesia, erupts every few years.

NATURAL HAZARDS

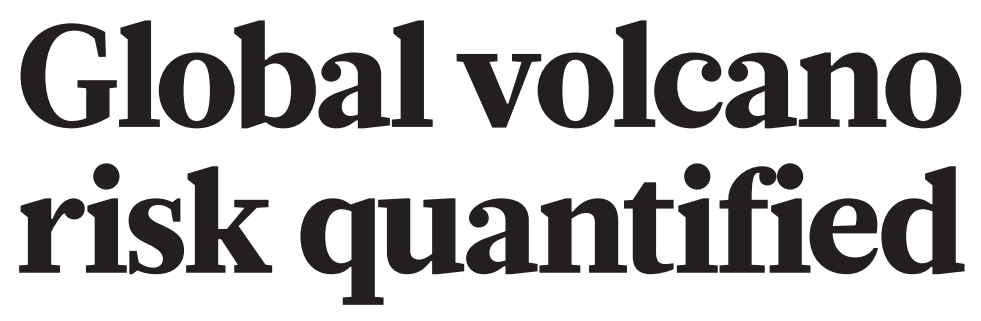

UN assessment aims to save lives by aiding planning.

\section{BY ALEXANDRA WITZE}

S wept away by mudslides, entombed in lava or suffocated under ash, nearly 280,000 people have died in volcanic eruptions during the past four centuries, but only now has humanity managed to quantify the risk posed by these fiery phenomena. The first detailed assessment of global volcanic risk - part of a larger international hazard assessment released on 4 March by the United Nations Office for Disaster Risk Reduction - aims to save lives by providing better information for risk planners and by showcasing effective response measures.

"For the first time, we really have a shared understanding of volcanic activity at the global scale," says Jean-Christophe Komorowski, a volcanologist at the Institute of Earth Physics in Paris, who contributed to the report. "This is a major turning point."

Eight hundred million people live within 100 kilometres of a volcano that could erupt. But the hazards differ greatly from place to place. High in the snow-capped Andes, an eruption might melt ice and send floodwaters rushing into nearby villages. In southeast Asia, a powerful eruption might blast ash over a wide area, causing roofs to collapse under the weight.

The report aims to put hard numbers on exactly who is at risk. It comes from a UK-led international network of institutions called the Global Volcano Model, working with the International Association of Volcanology and Chemistry of the Earth's Interior.

Team leaders sifted through a database of nearly 9,500 eruptions over the past 10,000 years kept by the Smithsonian Institution in Washington DC. They noted how often a particular volcano had erupted and what kind of physical hazards it posed. Then they tallied the number of people who now live within 10, 30 and 100 kilometres of that volcano and whether they live in places where eruptions have killed people before (see 'Mass destruction'). The result is a complete catalogue of the highest-risk volcanoes and a list of countries ranked by the number of residents in harm's way.

Researchers were surprised to find risk in places not typically thought of as highly volcanic. The Auvergne region of France, for instance, has been quiet in historic times. But it has had eruptions in the past few thousand years, putting it relatively high on the hazard scale because so many people live nearby. In New Zealand, the Auckland volcanic field - the eruptive history of which is not particularly well known - lies directly under the country's biggest city.

"Volcanoes are extremely attractive areas to 